\title{
Coda
}

\section{When Comedy Was King}

If death is a condition of memorialization, then slapstick must have been dead by 1939. Such, at any rate, would be the lesson of Twentieth Century-Fox's Technicolor extravaganza Hollywood Cavalcade, a two-million-dollar nostalgia romp through the early days of the film industry, released in the fall of that year. "'Hollywood Cavalcade" is destined to arouse in the hearts and minds of millions of theatre-goers all the glamour and romance of the bygone era of motion pictures," the program for the film's October 4 premiere declaimed. "From the days of Keystone Cops . . . bathing beauties ... slapstick comedies ... to mighty modern motion picture masterpieces ... here is a production which runs the gamut of Hollywood history!"' Hollywood had, of course, come very far from the early days of Keystone-style slapstick by the time Fox began production on this film (working title Falling Stars) the previous spring-so much so, in fact, that under Joseph Breen's watchful moral eye at the Production Code Administration, the filmmakers were not even allowed to use the word "pratfall," now deemed offensive. ${ }^{2}$ Yet as the weighting of the program's rhetoric indicates, it was upon the recreation of Hollywood's supposedly slapstick-flavored youth that the film's nostalgic project was hung, and upon slapstick's subsequent displacement that its historiography was built. It is accordingly Hollywood Cavalcade that provides a first ending to my story.

The film was the second in a three-picture cycle of nostalgia musicals produced by Fox around this time-the others being Alexander's Ragtime Band (1938), a fictionalized account of the birth of ragtime, the success of which seems to have 
inspired the cycle, and Swanee River (1940), a biopic about minstrel song composer Stephen Foster. All three films were identical in terms of their narrative template, depicting the history of their respective popular cultural forms-ragtime, the movies, minstrel songs - as a socially integrative story of union and reconciliation, structured around a heterosexual romance. ${ }^{3}$ It is thus as the story of one man's rise and fall and rise again, correlated with the vicissitudes of a love plot, that the narrative of Hollywood Cavalcade is arranged, offering a recounting of Hollywood's past that splices together elements of the lives of Mack Sennett, D. W. Griffith, and Cecil B. DeMille into the fictional career of one Michael Linnett Connors. (The protagonist's name is based on Sennett's birth name, Michael Sinnott). Journeying to Los Angeles in 1913, Connors (Don Ameche) rises quickly through the ranks of the early film industry, where, as an up-and-coming director, he accidentally "invents" the style of custard-pie slapstick and makes a comic star of his protégé, Molly Adair (Alice Faye), a Mabel Normand type who secretly loves him. Connors next pioneers the epic style of Griffithian historical spectacle after more serious ambitions take hold; in fact, it is while filming such a picture (with sets evocative of Intolerance) that Connors learns that Adair, tired of his workaholic tendencies, has married her costar, Nicky Hayden (Alan Curtis), sending Connors into a creative slump that derails his career. Resolution eventually comes years later, when Molly arranges Connors's return to the director's chair. Nicky unfortunately dies in an auto accident, leaving Molly and Connors free to declare their love for one another and boldly resolve to film a part-talkie together (it is now 1927). The film thus ends with a heterosexual reconciliation that restores Connors to his role as quasi-Promethean architect of early American film history: part Sennett, part Griffith, the inventor of film slapstick and the epic feature now also participates in the birth of the talkies. In the final shot, Molly and Connors embrace on a balcony overlooking Los Angeles, while, beside them, their producer intones: "It used to be a kind of game, the movies; and now look at it, a city ... filled with people who make the entertainment for all the peoples of the world."

It is to this idea of early filmmaking as a "kind of game" that the early slapstick sequences are dedicated. Bearing the burden both of the film's verisimilitude as historical recreation and of its appeal as nostalgia, these scenes are populated with an assemblage of familiar silent comedians-Ben Turpin, Chester Conklin, and most centrally, Buster Keaton-all playing themselves. As a "Movie of the Week" report in Life magazine put it, producer Darryl F. Zanuck had "summoned out of the past" these "memorable personages" to "romp across the screen exactly as they used to do in the years of the movies' uproarious childhood." " (Mack Sennett also appears as himself somewhat later in the film, making a speech at Molly and Nicky's anniversary party-despite the fact that the fictional Michael Connors has appropriated much of his biography.) Nor was this the only gesture toward verisimilitude. According to studio publicity, 
the film's recreations of early slapstick, in these and other scenes, involved the appearance of an authentic period camera- "used by the Sennett Company twenty-five years ago" and dusted off for the occasion from "its seat of honor in the Los Angeles Museum's collection of movie relics"- and were staged with the technical assistance of erstwhile Sennett director Mal St. Clair, who instructed actors "to impersonate the famous comics of yesteryear." 5 Yet these appeals to authenticity here function as little more than props for the film's more aggressive mythologizing of slapstick's origins. We have already had cause to note-in the previous chapter-how the film participated in the broader misapprehension of Keaton as a veteran of slapstick's Keystone days. ${ }^{6}$ More flagrant, though, is the film's depiction of slapstick's "birth." Keaton is called to set to perform a melodramatic scene with ingénue Adair and a mustachioed villain, whereupon he improvises an attack by picking up a custard pie left on the edge of the set and hurling it at his antagonist, accidentally hitting Molly instead. Keaton's improvised pie throwing not only disrupts the filming of the scene, brought to a halt so that Molly can clean up; it also breaks the scene's generic boundaries, pushing it outside of melodrama to provoke gales of laughter among the behind-the-camera personnel and inspiration for director Michael Connors. The film-within-the-film is subsequently completed not as melodrama but as a pie-throwing comedy. Next, in a two-minute sequence at a screening room, Connors's comedy is projected for his producers and, by proxy, us, the viewers: the film receives producer approval, and the studio places a daily order for five hundred custard pies at a local bakery. Thus, we are to believe, was slapstick invented. In the very process of "re-membering"-Barbara Myerhoff's term for the nostalgia that seeks the "reaggregation of . . . the figures who belong to one's life story" (here, early slapstick's)—the film instead significantly "misremembers" the past. ${ }^{7}$

Thus it was that the film's slapstick sequences were constructed-and, indeed, received-as the emblem of American cinema's youth, a cherished object of reminiscence abstracted from its own past. Without question, these sequences lay at the heart of Hollywood Cavalcade's success-at least to judge from contemporary reviews - and they prompted a surprisingly unquestioning nostalgia from the majority of critics. A reviewer for the weekly Variety waxed lyrical, moved to reflect on slapstick as an object of loss: "Views of film making in the days when a pie was worth five jokes, and when Keystone cops whirled recklessly through traffic to save distressed maidens, are hilariously reproduced. Something more than pantomime passed from films when sound entered the studios. A complete form of storytelling labeled slapstick, also disappeared." ${ }^{\prime 8}$ For the Film Daily's critic, there was no contradiction between the film's nostalgic appeal and its authenticity as historical spectacle: "There is nostalgic footage a-plenty for woven into the romantic fabric is the 'birth' of the custard pie and Keystone Cop slapstick, the 
advent of the bathing beauty school of cinema, the 'discovery' of the De Millean type of spectacle and, finally, the debut of sound by way of Al Jolson and 'The Jazz Singer.' ... The parade of veterans-Mack Sennett, Lee Duncan [owner of Rin Tin Tin], Ben Turpin, Chester Conklin, among them-heightens the authenticity." 9 No less an authority on American cinema's past than Terry Ramsaye similarly celebrated the slapstick sequences for their authenticity, claiming, in fact, that the comedy surpassed that of the original object: "There is a magnificent sequence of the most utter of Keystone comedy slapstick," Ramsaye wrote in a special review in Motion Picture Herald. "The audience found it just as funny as the original audiences of old Keystone did-perhaps funnier. The pie throwing was equally authentic and successful." ${ }^{10}$ Others, meanwhile, gave voice to a more interpreted nostalgia in explaining Hollywood Cavalcade's appeal, linking the film's mood of reminiscence to the industry's present crises. "Exhilarating, inspiring," one critic wrote. "[Hollywood Cavalcade] carries also a note of encouragement to picture production and exhibition personnel in these days when the industry faces, as it has faced before, a seemingly crucial period." ${ }^{12}$

So powerful was the film's recreation of Hollywood's early days as to prompt growing demand for a revival of old-style slapstick comedies and even rumors of Mack Sennett's return to filmmaking. "The great success of the early reels in 'Hollywood Cavalcade," commented the Herald, "is a demonstration that the public is in the mood for broad slapstick amusement." ${ }^{13}$ Capitalizing on Cavalcade's success, Sennett entered into discussions with Fox's production head, Darryl F. Zanuck, to produce a new Keystone-style feature, to be titled Left at the Altar or Love in a Pullman Car. ${ }^{14}$ While nothing came of these plans, other companies were soon catering to the growing demand for throwback comedy. Shortly after Cavalcade's release, RKO producer Max Gordon noted a "definite audience preference ... for laughter" and described his intent to produce "laugh picture $[s]$. . . of the type that Lloyd and Chaplin used to make." ${ }^{15}$ Meanwhile, a 1940 Herald article, titled "Trend toward Revival of Old Slapsticks," singled out two new firms specializing in slapstick reissues: the King of Comedy Film Corporation, which solely distributed Chaplin's Essanay films, and Motion Picture Jubilee Productions, offering comedies starring Ben Turpin, Snub Pollard, Mabel Normand, and others, "jazzed up with some 'screwball' commentary and sound effects." Commenting on the popularity of the films' screenings, Jubilee's president, Morton H. Miller, explained that older filmgoers were satisfying "a long sensed nostalgia for the old-time motion pictures, while the youthful film fan was relieved of a curiosity as to what silent pictures had to offer." ${ }^{16}$ A belief in old-time slapstick's salvific potential had, by this point, become a frequently voiced element of mainstream movie culture-an ironic destiny for the subversive spirit with which Keystone-style slapstick had once confronted the very mainstream to which it now offered renewal. 
But there it is again, in Hollywood Cavalcade too, the dividing line of sound-here the conclusion of a film whose operations as nostalgia depend upon a boundary beyond which Connor's and Adair's presumably continuing careers remain unrepresented and unrepresentable. Nostalgia, after all, requires a historiography grounded in rupture, in a change that permits neither of continuity (things were different then) nor of return (we can't go back); and in the historiography of slapstick, sound has long served that purpose, not only for the writers of Hollywood Cavalcade but for the broader legacy of twentieth-century scholarship on the form, extending from James Agee onward. As historian David Kalat astutely writes, "The history of the history of silent comedy has been a nostalgia industry since day one. By treating the advent of sound as a dividing line between Then and Now, any celebration of 'Then' turn[s] into a pining for something lost." ${ }^{17}$ This book has been an alternative tale of that "something lost," focused instead on the social and industrial currents that transformed what had once been the very emblem of cinematic modernity into an anachronistic vehicle for old-time reminiscence. In the process of telling this tale, the significance of sound has changed, no longer as a technological division separating the "art" of pantomime from its sound-era freefall, but as a media change that introduced the principle of difference upon which silent-era nostalgia could thrive. The advent of sound may not have constituted a Rubicon moment in the history of cultural or industrial forms, but it did become the first example of a media change around which the cultural memory of succession and the resulting affect of media nostalgia would be organized, with slapstick enshrined as nostalgia's fast track.

As such, slapstick's fate bespeaks the degree to which Americans by the 1930 s understood themselves to be living in the time of media. Cinematic forms like slapstick were now temporal markers for measuring cultural and, indeed, biographical life, "time machines," if you like, whose continued circulation either as pastiche or as reissues opened portals onto the youth of the movies as well as moviegoers' own youth. It is thus no accident that subsequent writers on the form so often engaged in a retrospective and personal recounting to clarify the stakes of their own investments. ${ }^{18}$ James Agee's semiautobiographical novel, $A$ Death in the Family (1957), returns to the slapstick tradition he had so famously analyzed in his 1949 essay, "Comedy's Greatest Era," only here in a spirit not of analysis but of remembrance: it opens with a boy Rufus and his father on a trip to the movies in 1915 to watch a Chaplin short, leaving the theater "wrapped in good humor, the memory of Charlie." ${ }^{19}$ It is in the same spirit that Walter Kerr would commence his magisterial 1975 survey, The Silent Clowns, by proclaiming a primordial kinship with the great clowns of the 1920s. "When I first saw Keaton I didn't simply laugh at him, I fused with him, psyche locked to psyche; I recognized him as something known before birth, whatever that says about me-I have, as I say, yearned in what may be called a nostalgic way to see their films again." ${ }^{20}$ 
Yet an understanding of slapstick's fate as a nostalgia industry should reckon not only with the first-order nostalgia of those like Agee and Kerr who "lived through" the transition, but also with later audiences who, beginning in the 1950s, only ever knew slapstick second hand, as an already recycled form on television and other home-viewing technologies, and for whom it subsequently became part of their childhood. In the case of slapstick, the history of this later recycling properly deserves another book (from whose authorship I recuse myself), yet its outline further testifies to the role of media change in structuring nostalgia for media artifacts, here related not to technologically derived changes in representation (as in the case of sound) but to subsequent changes in slapstick's media accessibility (through television, home video, and the like). To live in the time of media, after all, does not refer solely to the way personal reminiscence may be periodized according to media change, but also to the process of indefinite recycling and remediation that makes media history a permanently renewable platform for the affective investments of later generations. The lineaments of that history provide the second ending to this book.

Television will be our opening port of call, with the Three Stooges the outstanding instance of how "old-time" slapstick came to be packaged as kiddies' TV in the late 1950 s. Finally let go from Columbia's short subjects division in 1957-where they had starred in comic shorts for nearly a quarter century-the Stooges found unexpected new life on television, when, the following year, Columbia's Screen Gems division released the team's pre-1949 two-reelers for syndication. The sale attracted buyers in most of the nation's television markets, where the live-action shorts played on independent stations' weekday after-school schedules, creating what Variety described as a "highly favorable climate for slapstick" as children's programming. ${ }^{21}$ Ratings alone testify to the team's startling resurgence as children's entertainers-in Chicago, for instance, where they achieved a 41 percent share for their time slot by December 1958-so much so that the trio began ending their live shows by thanking young audiences for bringing them "out of retirement." 22 Soon, television producers began capitalizing on the Variety reporter's intuitions by raiding public domain silent-era titles, comedies especially, to create re-edited clip compilations as family shows, such as Paul Killiam's ABC series Silents, Please! (1960-1961) and the syndicated children's programs The Funny Manns (1961) and Fractured Flickers (1963-1964), most of which featured comedy redubbing of silent films. Simultaneous with these was a spate of clip compilations, such as Harold Lloyd's own Harold Lloyd's World of Comedy (1962) and the stretch of eight compilation films produced by Robert Youngson: The Golden Age of Comedy (1958), When Comedy Was King (1960), Days of Thrills and Laughter (1961), 30 Years of Fun (1963), MGM's Big Parade of Comedy (1964), Laurel and Hardy's Laughing '2os (1965), The Further Perils of Laurel and Hardy (1967), and Four Clowns (1970). Unexpectedly profitable, the films drew admiring commentary in the trade press for their success with a generationally diverse audience, "not only with the film 
buffs and oldsters, but with a whole new generation of film-conscious kids who will come to appreciate this comedy artistry for their very own. Who says there's no way to bridge the 'generation gap' today?" ${ }^{23}$

Yet the cycle of late 1950s/196os-era slapstick reissues was not without consequence for the form's ongoing banalization. With the late 1950 s revival of slapstick as after-school television, not only were the films now embedded more directly in children's culture than ever before but they were playing on a medium with a very different discursive identity from cinema, and this required negotiations regarding the limits of violent comedy as children's entertainment. As one reporter commented on the Stooges revivals in 1960, "Ever since the madcap Three Stooges zoomed . . . back into the limelight, . . certain factions have been taking potshots at the trio's wholesale use of "violence," adding that "the TV storm has been raised because television is an intimate medium that is going right into the home." ${ }^{24}$ The recycling of slapstick as kiddies' programming thus stumbled over a discontinuity in media identities, forcing slapstick into the center of debates about child-appropriate limits to comic spectacle that resulted in one final, unexpected mutation in the form: its cartoonification. One strategy for children's television producers and programmers who sought to capitalize on the juvenile slapstick vogue and yet sidestep the critiques that live-action violence invited was to turn some of the best-known slapstick clowns into cartoon figures. Hanna-Barbera would be the most notable company to take up the reins here, producing Laurel and Hardy and Abbott and Costello cartoons in the mid-196os. Meanwhile, Normandy Productions-headed by Norman Maurer, Moe Howard's son-in-law-launched The New Three Stooges animated series, which ran for over 150 episodes between 1965 and 1966, with live-action wraparounds featuring the aging trio (now Moe, Larry, and Curly-Joe De Rita). As Moe himself explained, the intent was to use animation as a way of redeeming knockabout as "safe" children's entertainment: the team, it was claimed, would tone down their eye gouging for the live-action introductions, instead consigning such "intentional" violence to the animated segments. One Herald-Tribune interview-titled "What Price Violence?"-clarified the strategy: "When we're live,' Moe explained, “we'll cut out the ... physical horseplay and substitute unintentional violence. . . . In other words, I won't purposely 'clunk' Curly or Larry, but if I'm carrying a ladder, let's say, and I make a quick turn, it could clip Curly on the bean-unintentionally. The deliberate stuff will be seen only in the cartoon segments." ${ }_{25}$ It is as though animation, precisely because of its abstraction from material reality, could be considered an innocuous, indeed inoculating, format for knockabout violence.

And might one not hypothesize that these various renegotiations of slapstick's cultural meanings-peaking here at the very moment when baby-boom youngsters were inheriting the tradition-played a role in slapstick's ongoing consignment to the realm of presocial nostalgia? We here recall the process of "miniaturization" 
broached in our earlier discussion of Babes in Toyland (1934): miniature objects invite a reverie that "skews the experience of the social by literally deferring it" and so cannot be separated from an asocial mode of apprehension. ${ }^{26}$ And slapstick was nothing, by this point, if not fully "miniaturized": cut up into clips and accompanied by ironic and distancing commentary or cast into cartoon form wherein the clowns' infant-proportioned bodies now romped around a "plasmatic" fantasy land (fig. 39). ${ }^{27}$ The form's thoroughgoing banalization (now by fixed association with kiddie audiences) was thus knotted on television screens to an ongoing miniaturization to produce a third term, infantilization, marking slapstick's consignment to a realm antecedent to the lived dialectics of social time.

The next port of call in our prospective history redeems this fate by virtue of another media switch-this time to the eight- and sixteen-millimeter home market for vintage films that, in the 1960 s and 1970s, turned growing boomers into a new generation of collectors. Of the various companies trading in vintage film during this era (Classic Films, Ken Films, and so forth), Blackhawk commands attention as the company best positioned to exploit the slapstick market. Previously operating primarily as a rental library for films on sixteen millimeter with optical sound, Blackhawk altered its business model in 1952 by launching its own releases for sale under what it called its Collector Series, among which were Laurel and Hardy silents from the Hal Roach Studios and Keystone comedies licensed by Mack Sennett's one-time backer, Roy Aitken. By the time David Shepard joined the staff as vice president of product development in 1973, the company was nurturing collectors' enthusiasms with more than a dozen new releases every month, as well as establishing standards for restoration that were unprecedented in the vintage film market. Existing company correspondence from the 1970s - approximately a quarter of which deals with comedy-reveals Shepard providing information to inquiring collectors, mailing them copies of film historian Kalton C. Lahue's studies of silent slapstick, and consulting with Academy of Motion Picture Arts and Sciences archivist Sam Gill on the restoration of Chaplin's Mutual shorts (1916-1917) and Roscoe Arbuckle's Fatty and Mabel Adrift (January 1916). ${ }^{28}$ We will thus also want to introduce to our prospective history figures like Lahue and Gill, whose publications-the coauthored history Clown Princes and Court Jesters (1970), as well as Lahue's lengthy streak of monographs on early cinema, including Kops and Custards (1968), Mack Sennett's Keystone (1971), and tellingly, Collecting Classic Films (1970)-became critical sources of information for the emerging collectors market, existing symbiotically with Blackhawk to restore a historicizing imperative to hobbyist enthusiasms. ${ }^{29}$

Perhaps a final reference to the work of literary theorist Susan Stewart can bring our argument home. In her groundbreaking study On Longing, Stewart introduces a celebrated distinction between the souvenir and the collection in terms of their respective relations to the past. The souvenir, she writes, "is not 


\section{Stooges Ready 'Fresh' TV Series}

\section{By SAMUEL D. BERNS}

HOLLYWOOD, March 31. - The high ratings garnered by hundreds of old Three Stooges' comedies, now in their sixth run in many of the 156 markets showing the Screen Gems syndicated show, has inspired "Larry, Moe and Curly Joe" to produce their own "fresh" film series expressly for television titled "Three Stooges Scapbook."

In an interview with Moe Howard, who formed the Three Stooges' partnership more than 25 years ago, and Norman Maurer, producer of the new

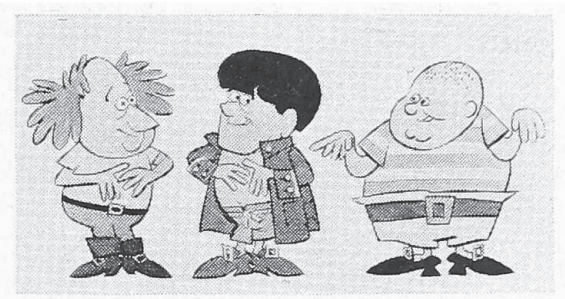

series, it was pointed out that the new format will include a special added feature. In addition to the live action, which will occupy about 15 minutes of the half-hour program, two fiveminute segments of animated cartoons are integrated in which the Stooges are cartoon characters carrying on their zany antics.

Howard called attention to the fact that the Stooges will eliminate any semblance of violence, such as "direct thumbing, pulling noses or slapping," which figured prominently in their old comedies.

"We are going directly into the home for family entertainment, and believe we can achieve high comedy without resorting to the kind of violence that kids are apt to imitate," Howard pointed out.
FIGURE 39. A trade report on Norman Maurer Productions' Three Stooges Scrapbook, one of the earliest efforts to repackage live-action slapstick in cartoon form for children's television. Samuel D. Berns, "3 Stooges Ready 'Fresh' TV Series," Motion Picture Daily, April 1, 1960. 
simply an object appearing out of context, an object from the past incongruously surviving in the present"; rather, souvenirs are "magical objects" that "transform history into private time" by "envelop[ing] the present within the past" of one's own life experiences. ${ }^{30}$ By contrast, the logic of the collection extracts from the past, both private and historical, in order to submit its artifacts to the present context of a classification: "The collection seeks a form of self-enclosure . . [that] replaces history with classification, with order beyond the realm of temporality." ${ }^{11}$ As souvenir, a past artifact has value as an anchor in one's own biographical encounters or experiences; as part of a collection, it serves as an item in a series in need of completion.

Scholars have qualified Stewart's distinction by suggesting that the two logics may in fact coexist (in the case, say, of a private collection), so that it would be more useful to think of the pairing as two poles on a spectrum rather than as exclusive alternatives. ${ }^{32}$ Still, the applicability of the distinction to the case at hand seems clear. By the 1960 s, the American slapstick tradition had long been a souvenir, arguably the preeminent souvenir of film history, its legacy sedimented for at least two generations as a portal into the private time of childhood and a token of a supposedly more authentic, primordial laughter ("when a pie was worth five jokes"). But the emergence of a collectors market spurred a shift in protocols toward classification and exhaustiveness, whose goal would be a perfect hermeticism. Undoubtedly such completion can never be materialized, given the archival absences that plague silent-era film, but it can be symbolized, its gaps "filled in" by a historical writing that stands in for the completion the collector desires. It is thus symptomatic, I think, that the preferred mode of scholarly expression for those boomer historians has come to be the filmography, a genre of slapstick historiography guided by rigorous protocols of identification that has reached a remarkable apex in recent years in publications like Brent Walker's magisterial resource Mack Sennett's Fun Factory (2010) and Richard Roberts's no less comprehensive cataloging of the Hal Roach Studios' output in Smileage Guaranteed (2013), as well as in Steve Massa's ongoing recovery of forgotten and marginalized comic performers, to name only some prominent examples. ${ }^{33}$ Nostalgia transcends itself, it would seem, when the souvenir founds a collection, even when that collection takes virtual form only, as a catalogue raisonné.

This is why I rehearse this sketch for a prospective history, in order finally to locate Hokum! within the very cultural processes it has analyzed. Because I am somewhere in there too, a kid watching the PBS series Harold Lloyd's World of Comedy on $\mathrm{BBC}_{2}$ in the early 1980 - not a baby boomer (those are my parents) nor a collector, but one who has, like others, found in nostalgia the imperative to historicize, the longing mark that would overcome itself through historiography. 